\title{
Origin of the Selective Electroreduction of Carbon Dioxide to Formate by Chalcogen Modified Copper
}

\author{
Rodrigo García-Muelas, ${ }^{\dagger}$ Federico Dattila, ${ }^{\dagger}$ Tatsuya Shinagawa, ${ }^{\ddagger}$ Antonio J. Martín, \\ Javier Pérez-Ramírez, ${ }^{*}+\odot$ and Núria López ${ }^{* \dagger}+\odot$ \\ ${ }^{\dagger}$ Institute of Chemical Research of Catalonia, The Barcelona Institute of Science and Technology, Av. Països Catalans 16, 43007 \\ Tarragona, Spain \\ ${ }^{\ddagger}$ Institute for Chemical and Bioengineering, Department of Chemistry and Applied Biosciences, ETH Zürich, Vladimir-Prelog-Weg \\ 1, 8093 Zurich, Switzerland
}

Supporting Information

ABSTRACT: The electrochemical reduction of atmospheric $\mathrm{CO}_{2}$ by renewable electricity opens new routes to synthesize fuels and chemicals, but more selective and efficient catalysts are needed. Herein, by combining experimental and first-principles studies, we explain why chalcogen modified copper catalysts are selective toward formate as the only carbon product. On the unmodified copper, adsorbed $\mathrm{CO}_{2}$ is the key intermediate, yielding carbon monoxide and formate as carbon products. On sulfur, selenium, or tellurium modified copper, chalcogen adatoms are present on the surface and actively participate in the reaction, either by transferring a hydride or by tethering $\mathrm{CO}_{2}$ thus suppressing the formation of $\mathrm{CO}$. These results highlight the active role of chalcogen centers via chemical steps and point toward basicity as the key descriptor for the stability and selectivity of these catalysts.

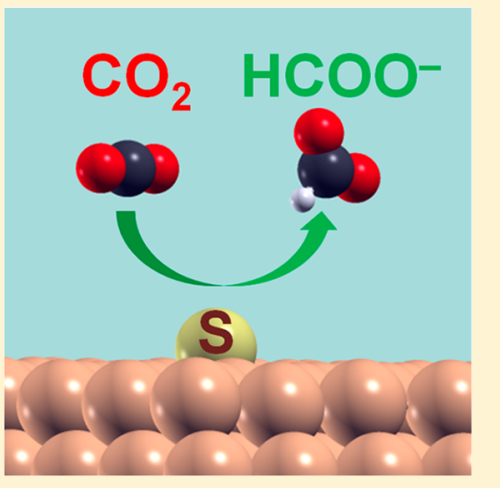

$\mathrm{T}$ he electrochemical $\mathrm{CO}_{2}$ reduction reaction $\left(\mathrm{eCO}_{2} \mathrm{RR}\right)$ driven by renewable electricity can mimic the natural photosynthetic cycle and thus is a key element to meet climate targets. ${ }^{1,2}$ In spite of the populated catalogue of catalysts identified, with carbon monoxide, hydrocarbons, and formate as more frequently reported products, ${ }^{3-5}$ this technology remains at an incipient stage as existing materials are suboptimal regarding activity, selectivity, stability, and scalability for practical purposes. ${ }^{6}$ These complications are related to the lack of robust structure-performance relationships, limited by (i) the complexity of the reaction network, (ii) the challenging application of in situ studies in electrochemical environments, and (iii) the simplifications in the models representing electrochemical processes at the molecular scale.

Theoretical attempts to explain the $\mathrm{eCO}_{2} \mathrm{RR}$ over welldefined transition metal surfaces ${ }^{8-11}$ combine Density Functional Theory (DFT) and the computational hydrogen electrode (CHE) approach. ${ }^{10,12,13}$ This strategy allows for solvent contributions to be introduced through approximate models, ${ }^{14-16}$ while electric potential and $\mathrm{pH}$ effects can be added as linear corrections. ${ }^{16,17}$ Neither the effect of the applied potential on adsorption nor the impact of $\mathrm{pH}$ on selectivity (known to control methane and ethylene formation ${ }^{18-22}$ ) are fully included in the simulations, although significant advances have been made lately (see ref 23 and references therein). On clean metals, the reaction starts with the adsorption of $\mathrm{CO}_{2}$, followed by a succession of protoncoupled electron transfers (PCETs), ${ }^{17}$ although decoupled steps have also been proposed; ${ }^{17,24,25}$ see Scheme 1. The DFTCHE model predicts medium-to-high overpotentials for $\mathrm{eCO}_{2} \mathrm{RR}$ and describes selectivity trends observed for $\mathrm{C}_{1}$ and $\mathrm{C}_{2}$ products on different metals and surface orientations. ${ }^{8,10,17,23}$ Carbon monoxide is the key intermediate for most $\mathrm{eCO}_{2} \mathrm{RR}$ products, with the exception of formate. The linear scaling relationships (LSRs) between the binding energies of different intermediates on transition metals ${ }^{26}$ impose constraints, limiting the optimization of metallic catalysts or alloys. ${ }^{8,9,27}$ As we show in the present letter, surface modifiers can break LSRs by adding chemical (potential-independent) steps, thus improving the selectivity control.

Copper is unique in that it reduces $\mathrm{CO}_{2}$ to compounds demanding more than two electron transfer steps with reasonable selectivity. ${ }^{2,4}$ Recent studies have pointed out that p-block elements ${ }^{5,24,29-34}$ can act as modifiers and that tiny amounts of sulfur ${ }^{29,30}$ and selenium ${ }^{29}$ switch the $\mathrm{eCO}_{2} \mathrm{RR}$ selectivity toward formate, otherwise a minor product, while largely inhibiting the undesired hydrogen evolution reaction (HER). The aim of our work is to unravel the mechanistic origin of the selectivity switch reported for the sulfur-modified copper catalyst, $\mathrm{Cu}-\mathrm{S}$, and illustrate if the effect persists for other chalcogenides. To this end, we have performed DFT

Received: October 21, 2018

Accepted: December 11, 2018

Published: December 11, 2018 
Scheme 1. (a) Simplified Reaction Mechanisms for the $\mathrm{eCO}_{2} \mathrm{RR}$ toward Formate/Formic Acid (Paths 1-2, in Olive and Yellow) and CO (Path 3, Red), and for the Parasitic HER (Path 4, Gray) on Clean Cu; ${ }^{28, a}$ (b) Reactions Mechanisms in Which the Chalcogens Act as Active Centers: $\mathrm{CO}_{2}$ Tethering (Path 6, Light Green), Heyrovsky-like Hydride Shuttle (Path 7, Dark Green), and the HER (Path 5, Black). ${ }^{b}$

a

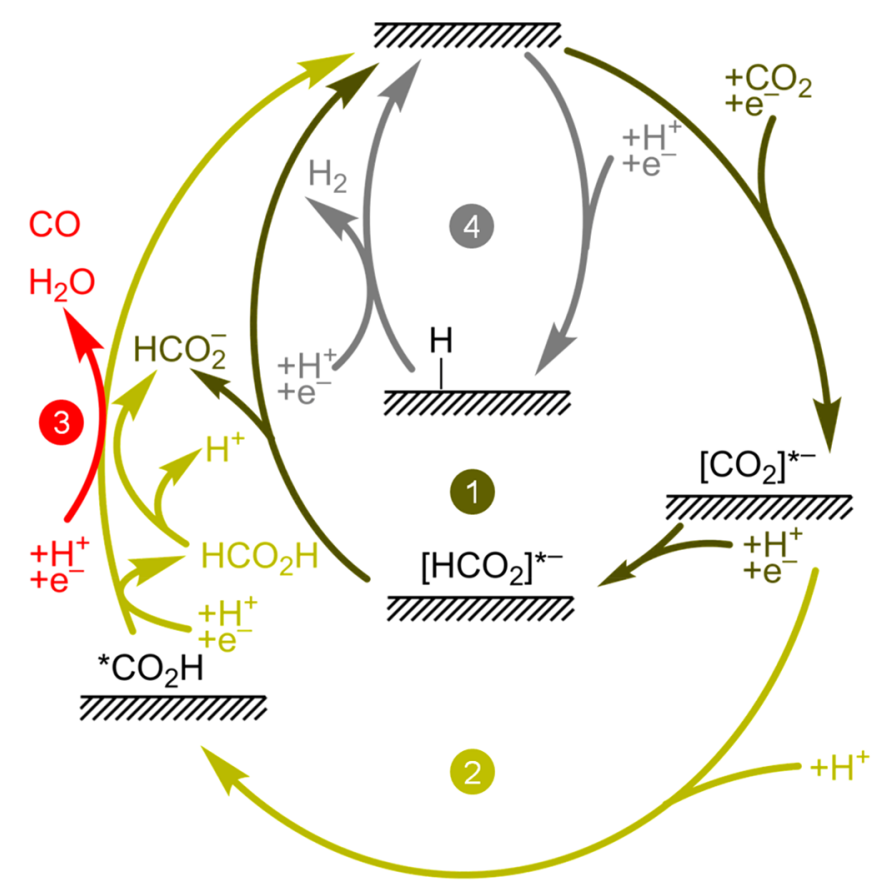

b

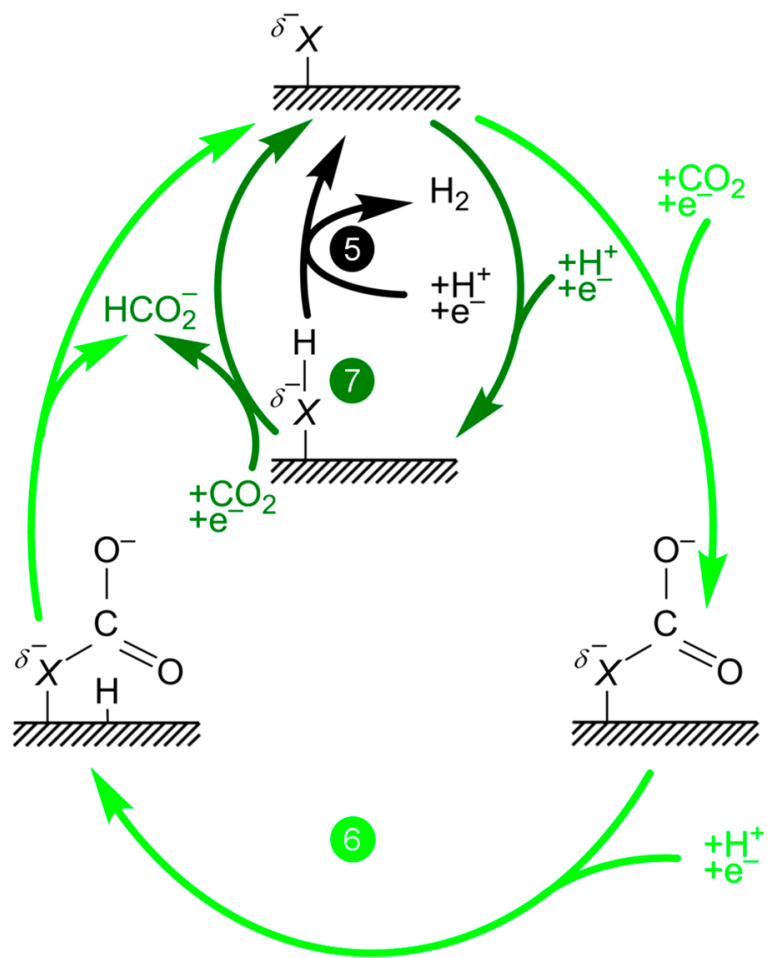

${ }^{a}$ The full mechanism is presented in Scheme S1. ${ }^{b}$ The charge of an adsorbed chalcogen, $\delta^{-}$, depends on the external potential $U$.

simulations for the systems including $\mathrm{O}, \mathrm{S}, \mathrm{Se}$, and $\mathrm{Te}$ as dopants and compared them to the experimental systems. The true state of O-containing samples is difficult to assess (see below).

We synthesized three copper catalysts from its oxidic $\mathrm{Cu}_{2} \mathrm{O}$ phase, modified by sulfur $(\mathrm{Cu}-\mathrm{S})$, selenium $(\mathrm{Cu}-\mathrm{Se})$, or tellurium $(\mathrm{Cu}-\mathrm{Te})$ via a solvothermal route. ${ }^{30}$ The fresh samples exhibited microsized aggregates containing nanometric particles (Figures S1-S4) with a chalcogen content of $1-3$ at. $\%$ relative to copper (Table 1 ). The chalcogens were uniformly distributed, as shown by energy dispersive X-ray spectroscopy coupled to scanning electron microscopy (EDXSEM, Figure 1a). As for the crystalline structures, $\mathrm{Cu}-\mathrm{S}, \mathrm{Cu}-$ $\mathrm{Se}$, and $\mathrm{Cu}-\mathrm{Te}$ exhibited $\mathrm{X}$-ray diffraction patterns assigned to $\mathrm{Cu}_{2} \mathrm{O}$ accompanied by traces of the metallic $\mathrm{Cu}$ phase (Figure S2), likely due to the rapid formation of a native oxide layer

Table 1. Double-Layer Capacitance, $C_{\mathrm{DL}}$ in $\mathrm{mF} \mathrm{cm}^{-2}$, and XPS- or EDX-Measured Chalcogen Elemental Content, before and after Electrocatalytic Testing, in Atomic Percentage Relative to $\mathrm{Cu}^{a}$

\begin{tabular}{lcllcc} 
& & \multicolumn{4}{c}{ relative content } \\
\cline { 3 - 6 } & $C_{\mathrm{DL}}$ & \multicolumn{1}{c}{$\mathrm{XPS}_{\text {fresh }}$} & $\mathrm{XPS}_{\text {used }}$ & $\mathrm{EDX}_{\text {fresh }}$ & $\mathrm{EDX}_{\text {used }}$ \\
$\mathrm{Cu}-\varnothing$ & 2.9 & $78.2 \pm 0.1$ & $77.9 \pm 0.1$ & 45.8 & 48.7 \\
$\mathrm{Cu}-\mathrm{S}$ & 1.4 & $3.4 \pm 1.0$ & $1.1 \pm 1.1$ & 0.6 & 0.6 \\
$\mathrm{Cu}-\mathrm{Se}$ & 2.3 & $2.3 \pm 2.2$ & $1.5 \pm 1.4$ & 0.2 & n.q. ${ }^{b}$ \\
$\mathrm{Cu}-\mathrm{Te}$ & 2.8 & n.q. & $10.0 \pm 8.2$ & 1.1 & 0.7
\end{tabular}

${ }^{a}$ For the $\mathrm{Cu}_{2} \mathrm{O}$-derived $\mathrm{Cu}$ catalyst $(\mathrm{Cu}-\varnothing)$, the percentages refer to oxygen. ${ }^{b}$ n.q. nonquantifiable. over the metallic copper particles when exposed to air. ${ }^{33}$ The introduction of the chalcogen modifiers did not alter the crystallite size. In addition, as chalcogens are present at low concentrations they likely prevented the identification of any related bulk chalcogen reflections. The presence of chalcogen species on the topmost surface (approximately $1 \mathrm{~nm}$ ) of the synthesized catalysts was clearly indicated by the time-of-flight secondary ion mass spectroscopy (ToF-SIMS) analysis (Figure S5). X-ray photoelectron spectroscopy (XPS) analysis suggested a very limited presence of surface chalcogenide phases in the as-synthesized materials, as shown for measurements before $\mathrm{eCO}_{2} \mathrm{RR}$ testing (Figure $1 \mathrm{~b}$; see signal at binding energies of ca. 162,54 , and $573 \mathrm{eV}$ for $\mathrm{Cu}_{x} \mathrm{~S}, \mathrm{Cu}_{x} \mathrm{Se}$, and $\mathrm{Cu}_{x} \mathrm{Te}$, respectively). The chalcogen-free catalyst $(\mathrm{Cu}-\varnothing)$ was prepared by skipping the addition of chalcogen species ${ }^{29,30}$ (see Experimental Procedures in Section S1), resulting in unmodified $\mathrm{Cu}_{2} \mathrm{O}$ particles (see Figure S3).

$\mathrm{Cu}-\mathrm{Se}$ and $\mathrm{Cu}-\mathrm{Te}$ exhibit slightly better catalytic performance than $\mathrm{Cu}$ with a mild preference for $\mathrm{HCOO}^{-}$among the $\mathrm{eCO}_{2} \mathrm{RR}$ products measured with chronoamperometry (CA) at $-0.6 \mathrm{~V}$ vs Reversible Hydrogen Electrode (RHE), Figure 1c. In contrast, over $\mathrm{Cu}-\mathrm{S}, \mathrm{HCOO}^{-}$is the main carbon product, being in equal proportion with $\mathrm{H}_{2}$ whereas only trace amounts of $\mathrm{CO}$ were detected. The $\mathrm{Cu}-\mathrm{S}$ becomes more selective toward formate at higher overpotentials until the presence of $\mathrm{CO}$ and more complex products, typically associated with clean copper, becomes detectable at $-0.9 \mathrm{~V}$ vs RHE (Figures S6-S7). ${ }^{35}$ At $-0.8 \mathrm{~V}$, the incipient volcano-like behavior in terms of selectivity observed at $-0.6 \mathrm{~V}$ manifests now clearly (Figure 1c),suggesting the presence of a general effect modulated by the nature of the chalcogen. Comparison of our 

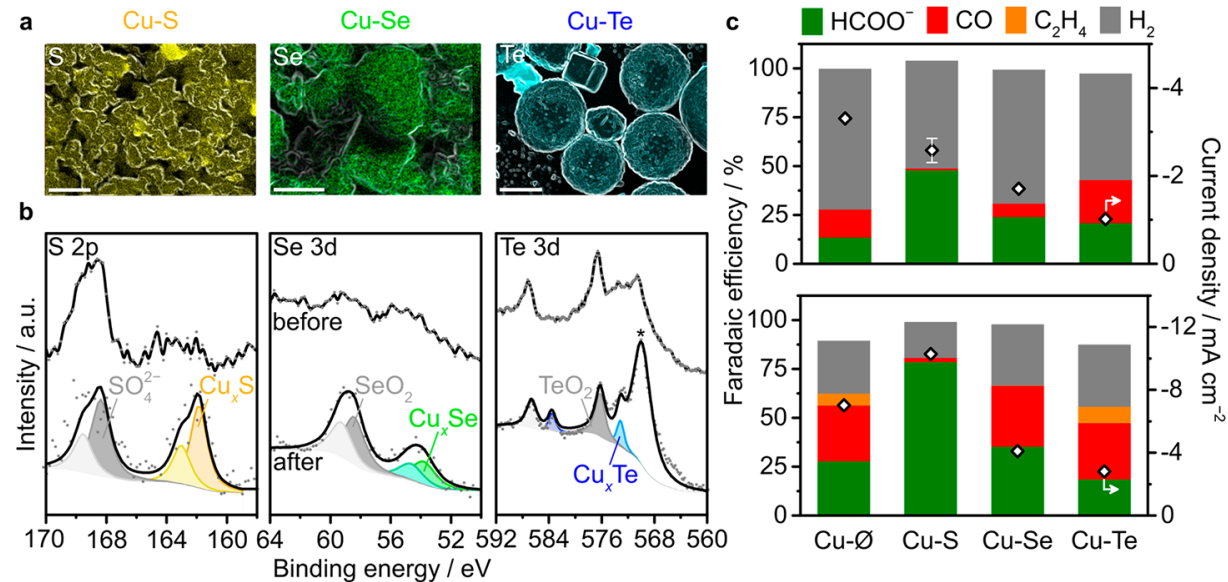

Figure 1. (a) EDX elemental maps of chalcogen elements for the corresponding fresh catalysts. White contours indicating the particle borders are added as a visual aid (see Figure S4). Scale bars: $2 \mu \mathrm{m}$. (b) Chalcogen XPS spectra before and after the $\mathrm{eCO}_{2} \mathrm{RR}$ testing at $-0.6 \mathrm{~V}$ vs RHE showing their presence after reaction. The peak indicated by asterisk (*) originates from the Auger emission in the Cu LMM region. (c) Product distribution over the copper-chalcogen catalysts, obtained by chronoamperometry at -0.6 (top) and $-0.8 \mathrm{~V}$ (bottom) vs RHE for $1.5 \mathrm{~h}$ in $0.1 \mathrm{M}$ $\mathrm{KHCO}_{3}$ saturated with $\mathrm{CO}_{2}$ (pH 6.7). Polycrystalline copper ${ }^{10}$ yields around $10 \%$ of both $\mathrm{HCOO}^{-}$and $\mathrm{CO}$ at $-0.6 \mathrm{~V}$, and $20 \% / 30 \%$, respectively, at $-0.8 \mathrm{~V}$. Further tests regarding the electric potential dependence and the role of alkaline cations are presented in Figures S6-S8 and Section S3.

pure $\mathrm{Cu}(\mathrm{Cu}-\varnothing)$ with polycrystalline, oxide-derived $\mathrm{Cu}$ reveals close similarities in product distribution, ${ }^{10}$ suggesting the removal of oxygen atoms from the copper surface under reaction conditions. In situ studies on oxide-derived copper catalysts have hinted at the presence of oxygen near the surface. $^{32,36,37}$ Nevertheless, the absence of such an oxidic phase has also been suggested ${ }^{33}$ and the promotion of carbon products formation was associated with grain boundaries. $^{33,34,38}$ Under the $\mathrm{eCO}_{2} \mathrm{RR}$ conditions, the surface of the electrocatalysts reconstructs (Figure S1) and the chalcogen content seems to decrease within the limited accuracy at such low concentrations (Table 1). Accordingly, XPS excitations around the $\mathrm{Cu} 2 \mathrm{p}$ peak showed the presence of $\mathrm{Cu}_{2} \mathrm{O}$ and $\mathrm{Cu}^{2+}$ (Figure S9), whereas peaks compatible with the copper chalcogenide phases built up (Figure $1 \mathrm{~b}$; Tables 1, S1). ${ }^{39}$ The broad peaks at higher binding energies in Figure $1 \mathrm{~b}$ are ascribable to oxidic phases, ${ }^{40}$ presumably formed upon exposure of the chalcogenides samples to air during characterization. $^{41}$ Further ToF-SIMS analysis confirmed the increase in the relative abundance of chalcogen on the topmost layer upon the reaction (Figure S5). Upon the restructuring process, the surface remains populated by chalcogen atoms, although some leaching occurs. ${ }^{30}$ We remark that the presence of copper chalcogenide phases after the $\mathrm{eCO}_{2} \mathrm{RR}$ testing is not expected from a thermodynamic point of view, because Pourbaix diagrams predict metallic copper as the most stable phase under operation conditions (Figure S10); however, small domains cannot be fully discarded. In summary, the unmodified catalyst $(\mathrm{Cu}-\varnothing)$ can be identified as polycrystalline $\mathrm{Cu}$ under operation conditions, since (i) the removal of oxygen atoms or hydroxyl groups is largely favored (Tables S2 and S3) and (ii) the product distribution of $\mathrm{Cu}-\varnothing$ follows that of polycrystalline $\mathrm{Cu}$ (Figure 1c). Therefore, the selectivity patterns observed for $\mathrm{Cu}-\mathrm{S}, \mathrm{Cu}-\mathrm{Se}$, and $\mathrm{Cu}-\mathrm{Te}$ can be ascribed to the chalcogen modifier.

To unravel the origin of the selectivity patterns, polycrystalline $\mathrm{Cu}$ was modeled by the lowest energy $\mathrm{Cu}(111)$ surface. Our calculations show that the results of the $\mathrm{Cu}(211),(110)$, and (100) facets yield qualitatively the same results, Figure S11. In the model, the chalcogens $(X=\mathrm{O}, \mathrm{S}, \mathrm{Se}, \mathrm{Te})$ are added as adatoms sitting on surface fcc sites (Table S2) leading to a relative composition of 2.7 at. $\%(X=1, \mathrm{Cu}=36)$ mimicking the experimental content, Table 1 . Other structural models were tested but found less stable (Table S2). The removal of S, $\mathrm{Se}$, and $\mathrm{Te}$ as $\mathrm{H}_{2} \mathrm{~S}, \mathrm{HSe}^{-}$, and $\mathrm{H}_{2} \mathrm{CO}_{2} \mathrm{Te}$ occurs at more negative potentials than $U=-0.92,-1.06$, and $-0.87 \mathrm{~V}$ vs RHE, respectively (Table 2 ), explaining why all $\mathrm{Cu}-X$ systems

Table 2. Computed Properties of the Chalcogen Modified $\mathrm{Cu}(111)$ Surface $^{a}$

\begin{tabular}{lcccccc}
\multicolumn{1}{c}{ system } & $\Delta G_{\mathrm{H}_{2} X}$ & $\Delta G_{\mathrm{HX}}$ & $\Delta G_{X_{\mathrm{CO}_{2} \mathrm{H}_{2}}}$ & $q_{X^{*}}$ & $\varepsilon_{\mathrm{p}}-\varepsilon_{\mathrm{F}}$ & $\Delta\left(\varepsilon_{\mathrm{d}}-\varepsilon_{\mathrm{F}}\right)$ \\
$\mathrm{Cu}-\mathrm{O}$ & -1.28 & -0.84 & +1.86 & -0.93 & -2.50 & -0.16 \\
$\mathrm{Cu}-\mathrm{OH}$ & -0.60 & -0.16 & - & -0.59 & -4.22 & -0.11 \\
$\mathrm{Cu}-\mathrm{S}$ & +0.92 & +0.94 & +2.95 & -0.59 & -1.61 & -0.07 \\
$\mathrm{Cu}-\mathrm{Se}$ & +1.22 & +1.06 & +3.74 & -0.43 & -1.28 & -0.05 \\
$\mathrm{Cu}-\mathrm{Te}$ & +1.71 & +1.48 & +0.87 & -0.21 & -0.88 & -0.07
\end{tabular}

${ }^{a} \Delta G_{\mathrm{H}_{2} \mathrm{X}}, \Delta G_{\mathrm{HX}^{-}}, \Delta G_{\mathrm{XCO}_{2} \mathrm{H}_{2}}$ : desorption energies for the chalcogens to produce $\mathrm{H}_{2} \mathrm{X}, \mathrm{H} X^{-}$, and $\mathrm{XCO}_{2} \mathrm{H}_{2}(X=\mathrm{O}, \mathrm{S}, \mathrm{Se}, \mathrm{Te})$, in eV. $q_{X^{*}}$ : Bader charges of the adsorbed chalcogen, in $\mathrm{e}^{-} \mathrm{l} . \varepsilon_{\mathrm{p}}-\varepsilon_{\mathrm{F}}$ : center of the chalcogen $\mathrm{p}$-band with respect to the Fermi level of the system, in eV. $\Delta\left(\varepsilon_{\mathrm{d}}-\varepsilon_{\mathrm{F}}\right)$ : d-band center shift for the adjacent $\mathrm{Cu}$ atoms upon anchoring of the chalcogen, in $\mathrm{eV}$.

were stable at the working potentials from -0.6 to $-0.8 \mathrm{~V}$ vs RHE. $^{30}$ At more cathodic potentials than -0.90 vs RHE, the $\mathrm{Cu}-\mathrm{S}$ performance starts resembling that of polycrystalline copper, ${ }^{10}$ Table 2 and Figures S6. The stability of the $\mathrm{Cu}-\mathrm{S}$ system was further tested, Figures S12-S13, suggesting the progressive loss of sulfur from the surface at deeper cathodic potentials.

To understand the mechanistic implications of the $\mathrm{eCO}_{2} \mathrm{RR}$ on $\mathrm{Cu}$, we start by analyzing the reactions listed in Scheme 1a where the parasitic hydrogen evolution reaction is also presented. In the reaction network, either coupled or sequential proton and electron transfers appear, and their relative contributions are given by their different dependence on the potential and the interface $\mathrm{pH}$. To elucidate the origin of the selectivity switch imposed by the chalcogen modifier, we modeled $\mathrm{CO}_{2}$ adsorption as an electron transfer process and 

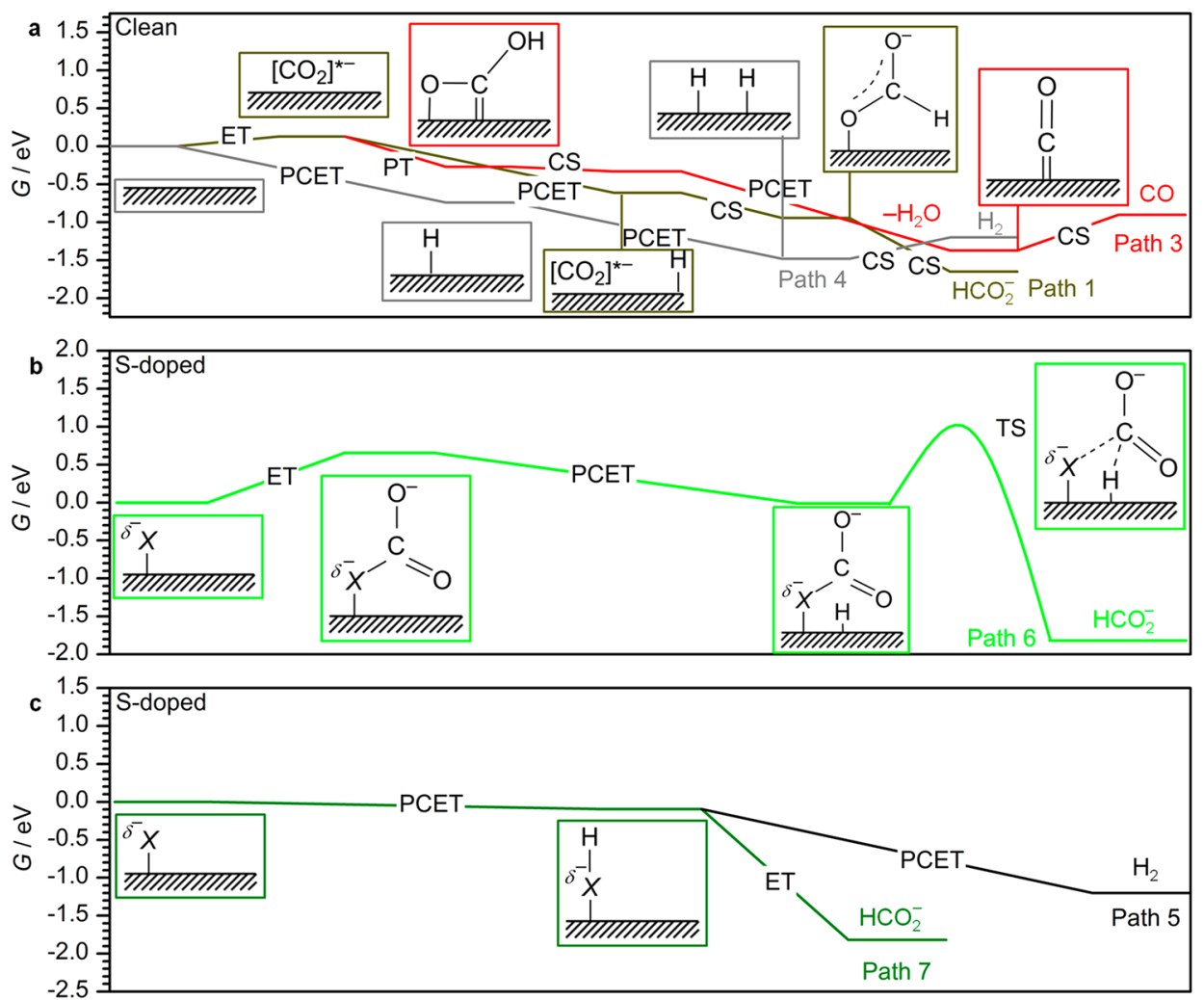

Figure 2. Gibbs free energy profiles on clean and chalcogen modified $\mathrm{Cu}(111)$ surfaces at $U=-0.6 \mathrm{~V}$ vs $\mathrm{RHE}$. (a) Electrochemical $\mathrm{CO}_{2}$ reduction toward formate (path 1, olive), CO (path 3, red), and hydrogen evolution reaction (path 4, gray) on clean $\mathrm{Cu}(111)$ ). Path 2 is also downhill from $\mathrm{CO}_{2}{ }^{*-}$ and is omitted for simplicity. For S-modified surfaces (b) presents path 6 starting from tethered $\mathrm{CO}_{2}{ }^{*-}$ toward formate and (c) the Smediated formate path 7 and HER. PCET: proton-coupled electron transfer. ET: electron transfer. PT: proton transfer. CS: chemical step. TS: transition state in CS. The profiles for $U=0.0$ and $-0.8 \mathrm{~V}$ vs RHE are shown in Figure S16, and those for other chalcogens, in Figure S17.

decoupled all the other steps along the whole reaction network when possible. ${ }^{17,42}$ The rate-determining step in the $\mathrm{eCO}_{2} \mathrm{RR}$ process is the difficult $\mathrm{CO}_{2}$ adsorption both on pure metal electrodes and in molecular catalysts. ${ }^{3,17,24}$ Raman spectroscopy has recently evidenced that the resulting carboxylate species is the first intermediate in the $\mathrm{CO}_{2}$ conversion to formate on copper. $^{43,44}$ From a mechanistic perspective, successful $\mathrm{CO}_{2}$ adsorption and activation imply the endothermic bending of the $\mathrm{O}-\mathrm{C}-\mathrm{O}$ bond, which requires $3.05 \mathrm{eV}$ for the neutral molecule but only $1.23 \mathrm{eV}$ for the negatively charged species, Figure S14. Therefore, its activation implies the electron transfer to its high lying LUMO. ${ }^{45}$ On the surface, $\mathrm{CO}_{2}{ }^{*-}$ can adopt four possible conformations, ${ }^{17}$ depending on the surface potential, Figure S15a. The most stable adsorbed structure at $U=-0.6 \mathrm{~V}$ is $\eta_{2(\mathrm{C}, \mathrm{O})}$, where both $\mathrm{C}$ and $\mathrm{O}$ are bonded to the surface.

Then a proton can be adsorbed onto the copper surface as $\mathrm{H}^{*}$ through a PCET step, path 1 in Scheme la, reacting with the carboxylate via a chemical step yielding monodentate $\mathrm{HCOO}^{*-}$, which desorbs as formate, Figure S15b, ${ }^{46}$ similar to $\mathrm{CO}_{2}$ reduction on $\mathrm{PdH}_{x}{ }^{17} \mathrm{~A}$ proton from solution is transferred to a terminal oxygen of $\mathrm{CO}_{2}{ }^{*-}$, giving rise to a carboxyl intermediate (path 2) that reacts with $\mathrm{H}^{*}$ to produce formic acid. Formic acid desorbs spontaneously and converts to formate due to the solution's $\mathrm{pH}$ (buffered at 6.7). Alternatively, the $\mathrm{COOH}^{*}$ intermediate decomposes to $\mathrm{CO}^{*}$ and water through either decoupled or concerted protonelectron transfer, path 3. The desorption of $\mathrm{CO}$ from $\mathrm{Cu}$ is endergonic, ${ }^{9}$ Figure 2a, thus allowing further reduction toward methanol and hydrocarbons. ${ }^{10}$ More cathodic potentials can stabilize the $\mathrm{CO}_{2}{ }^{*-}$ intermediate, thus simultaneously increasing the Faradaic efficiency or production of $\mathrm{HCOO}^{-}$ and $\mathrm{CO}$, until mild overpotentials are reached. ${ }^{10}$ The parasitic HER, by contrast, occurs through either a classical VolmerTafel mechanism, path 4, or a Volmer-Heyrovsky mechanism, omitted here for simplicity. As both $\mathrm{eCO}_{2} \mathrm{RR}$ and HER have $\mathrm{H}^{*}$ as a common intermediate, a mild metal-hydrogen bonding strength promotes both reactions. ${ }^{47}$ Applied to other transition metals, the reaction network in Scheme 1a predicts that they are poor formate-producing catalysts. ${ }^{23,48,49}$

The energy profile for $\mathrm{Cu}$ shown in Figure $2 \mathrm{a}$ at $\mathrm{U}=-0.6 \mathrm{~V}$ can be explained as follows: the markedly endergonic $\mathrm{CO}_{2}$ adsorption, Table S4, requires considerable overpotentials to trigger its reduction. The HER largely predominates at potentials more anodic than $-0.8 \mathrm{~V}$. As $\mathrm{CO}_{2}$ adsorption becomes more exergonic, paths 1 and 2 start competing with the HER (path 4). At higher overpotentials, the increasingly larger $\mathrm{CO}_{2}{ }^{*-}$ coverage enhances the production of formate and $\mathrm{CO},{ }^{50}$ accounting for the concomitant HER decrease. In our energy profiles, Figure $2 \mathrm{a}$, the HER is preferable over the $\mathrm{CO}_{2}$ reduction. The larger Faradaic efficiency toward formate could come from mass-transport phenomena ${ }^{19,51,52}$ (local $\mathrm{pH}$ at the interface, local $\mathrm{CO}_{2}$ concentration) not included in our model.

Modification of the copper surface with chalcogen $(X)$ adatoms leads to stable configurations with a polarized $X-$ metal bond $\left(X^{\delta-}\right)$ according to the Bader charges of $\delta=-0.93$, - 0.59, - 0.43, and $-0.21 \mathrm{le}^{-1}$ for $\mathrm{O}, \mathrm{S}$, Se, and Te respectively, Table S3. Along the series, the bond is more covalent as the partially empty p-states of the chalcogens lie 
closer to the highest, unperturbed $\mathrm{Cu}$ bands (the d-band is invariant; see Tables 2 and S3). At more negative potentials, ${ }^{53}$ the partial charge of the chalcogens, $X^{\delta-}(U)$, increases to $\delta=$ $-0.98,-0.76,-0.66$, and $-0.53 \mathrm{le}^{-} \mid$. The $X^{\delta-}$ surface site acts as a nucleophile to trap $\mathrm{CO}_{2}$ concomitant with an electron transfer, producing a chalcocarbonate $X^{\delta-} \mathrm{CO}_{2}{ }^{*-}$, path 6 in Scheme $1 \mathrm{~b}$. The computed free energies for S-decorated $\mathrm{Cu}$ (new paths 5, 6, and 7) are shown in Figure 2. Due to its geometry, $\mathrm{X}^{\delta-} \mathrm{CO}_{2}{ }^{*-}$ cannot form $\mathrm{CO}$, as it would imply breaking the $\mathrm{C}-X$ and $\mathrm{C}-\mathrm{O}$ bonds simultaneously. In parallel, a proton can adsorb on the neighboring $\mathrm{Cu}$ from the solution with an electron from $\mathrm{Cu}$ to form $\mathrm{H}^{*} .{ }^{42}$ The reaction proceeds with $\mathrm{H}^{*}$ attacking the carbon atom in $\mathrm{X}^{\delta-} \mathrm{CO}_{2}{ }^{*-}$ to produce formate, as indicated by the inset labeled TS in Figure $2 \mathrm{~b}$. This potential-independent chemical step presents an activation energy of $1.02 \mathrm{eV}$. The $X^{\delta-}$ site can also attract protons to produce $X^{\delta-} \mathrm{H}$, paths 5 and 7 in Scheme $1 \mathrm{~b}$. This species can attack either a proton or a $\mathrm{CO}_{2}$ in the solution, to produce hydrogen (HER path 5) or formate (path 7) respectively in Heyrovsky-like mechanisms. Paths 6 and 7 agree with the Tafel plot in Figure S7, which indicates that the rate-determining step for the reaction involves a single electron transfer (slope $120 \mathrm{mV} \mathrm{dec}^{-1}$ ). Finally, the presence of the chalcogen prevents the adsorption of $\mathrm{CO}_{2}$ on its neighborhood (destabilizing adsorption by $0.53,0.27$, and $0.12 \mathrm{eV}$ for first, second, and third nearest $\mathrm{Cu}$ sites, respectively), blocking unselective paths occuring on $\mathrm{Cu}$-only sites, Figure 2.

The energy profiles in Figure 2 enable the rationalization of the experimental catalytic trends over $\mathrm{Cu}-\mathrm{S}, \mathrm{Cu}-\mathrm{Se}$, and $\mathrm{Cu}-$ Te in Figure 1c. Since all steps in path 7 become exergonic from $U=-0.6 \mathrm{~V}$ vs RHE toward more cathodic potentials and the chalcogen atom destabilizes path 2 , the chalcogen centers become highly selective for the $\mathrm{eCO}_{2} \mathrm{RR}$ toward formate. As the formation of $\mathrm{XH}^{*}$ becomes more endergonic for heavier chalcogens, the activity of paths 5 and 7 is reduced along the chalcogen series (Table S4). As already noted, the blocking effect of $\mathrm{Se}$ and $\mathrm{Te}$ in neighboring $\mathrm{Cu}$ atoms is milder than that of S, Table S4, in line with the experimental trends observed in Figure 1.

The differences in activity and selectivity can be traced back to an intrinsic property of the adsorbed chalcogenides as both the tethering of $\mathrm{CO}_{2}$ (Figure 3a) and the formation of $\mathrm{XH}^{*}$ (Figure $3 b$ ) depend on the donor ability of $X$. Figure $3 c-d$ compile the key energy figures in paths 6 and 7 as a function of the basicity obtained as the p-band center of the chalcogen. ${ }^{54}$ In Figure $3 c$ (path 6) the low basicity enhances the stability of the $\mathrm{XCO}_{2}{ }^{*-}$ adsorbate, while higher basicity makes $\mathrm{HCOO}^{-}$ formation more exergonic. In Figure 3d (path 7), the limiting factors are the formation of $\mathrm{XH}^{*}$ and formate, where the former becomes more endergonic at larger basicities. In turn the HER is controlled by $\mathrm{H}$ adsorption on $\mathrm{Cu}$ (gray) and does not depend on the nature of the adatom. The optimal crossing point between the stability of the key intermediate and formate appears at -2.5 (path 6) and $-2.2 \mathrm{eV}$ (path 7), respectively. Thus, in both cases the chalcogen that shows the closest value is sulfur, which is in agreement with its unique catalytic performance among the family of chalcogen modifiers identified in Figure 1. It is also significant that the stability of the chalcogens on the surface correlates with the basicity, Figure S18.

In summary, the selective production of formate upon chalcogen modified copper is due to (i) the presence of basic sites where $\mathrm{CO}_{2}$ is tethered blocking its dissociation toward
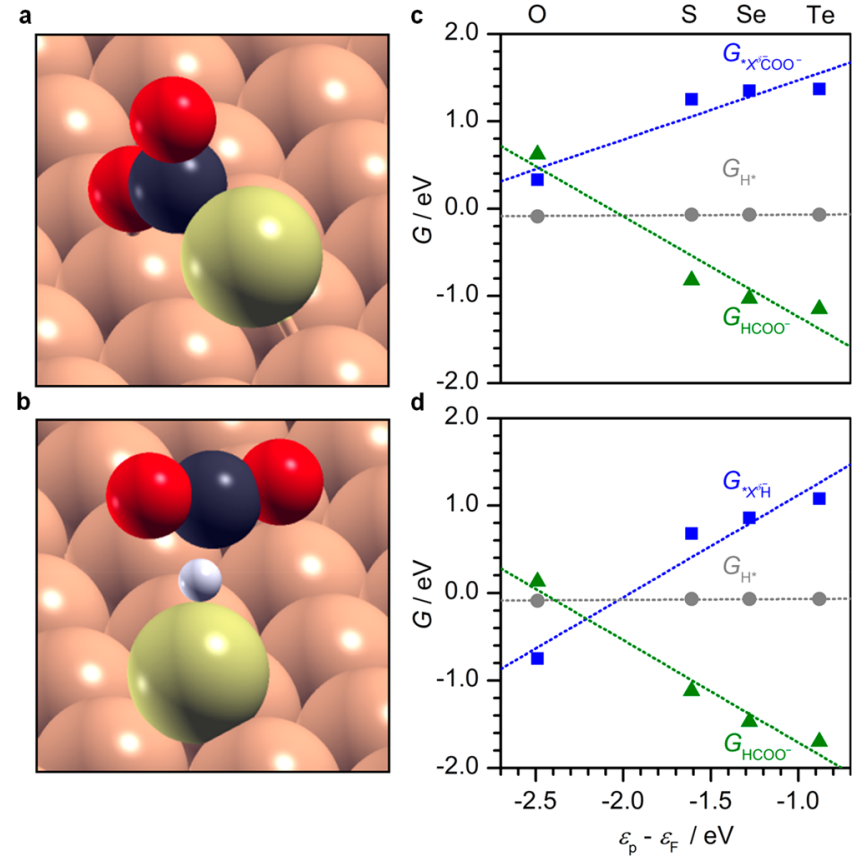

Figure 3. Most important intermediates for formate production (a) via $\mathrm{CO}_{2}$ tethering on the chalcogen adatom or (b) via the Heyrovsky mechanism (path 6 and 7 in Scheme 1, respectively). (c-d) Gibbs energies $(U=0.0 \mathrm{~V}$ vs RHE) of the crucial intermediates as a function of the basicity of the chalcogen, computed as the center of the chalcogen $\mathrm{p}$-band. Blue dots correspond to the energy of the precursors $\mathrm{X}^{\delta-} \mathrm{CO}_{2}{ }^{*-}$ and $X^{\delta-} \mathrm{H}$, respectively shown in the $(\mathrm{a}-\mathrm{b})$ panels, while the energy of $\mathrm{HCOO}^{-}$is shown in green. The largest activity is expected when the green and blue lines cross as the process will be isoenergetic. Gray dots represent the adsorption energy of hydrogen on copper atoms in the vicinity of $X$. Lines were added as a guide to the eye.

$\mathrm{CO}$, (ii) the ability of chalcogens to directly transfer hydrides to $\mathrm{CO}_{2}$, and (iii) the effective blocking of unselective paths on the surrounding $\mathrm{Cu}$ atoms. Our results point out the role of chemical steps in electrochemical processes.

\section{ASSOCIATED CONTENT}

\section{Supporting Information}

The Supporting Information is available free of charge on the ACS Publications website at DOI: 10.1021/acs.jpclett.8b03212.

Experimental procedures, computational details, cation effect, supplementary schemes, figures, tables, and references (PDF)

\section{AUTHOR INFORMATION}

\section{Corresponding Authors}

*E-mail: jpr@chem.ethz.ch (J.P.-R.).

*E-mail: nlopez@iciq.es (N.L.).

ORCID $\odot$

Rodrigo García-Muelas: 0000-0002-2219-5027

Javier Pérez-Ramírez: 0000-0002-5805-7355

Núria López: 0000-0001-9150-5941

\section{Notes}

The authors declare no competing financial interest.

The DFT data that support the findings of this study are available in ioChem-BD ${ }^{55}$ at DOI 10.19061/iochem-bd-1-92. 


\section{ACKNOWLEDGMENTS}

We are thankful for the financial support from MINECO (Grant Number CTQ2015-68770-R), ETH Zurich, and the European Union under Projects A-LEAF (732840-A-LEAF) and ELCoREL (721624-ELCOREL). The ScopeM of ETH Zurich and the Barcelona Supercomputing Centre (BSC-RES) are thanked for access to their facilities and generous computational resources.

\section{REFERENCES}

(1) Kondratenko, E. V.; Mul, G.; Baltrusaitis, J.; Larrazábal, G. O.; Pérez-Ramírez, J. Status and Perspectives of $\mathrm{CO}_{2}$ Conversion into Fuels and Chemicals by Catalytic, Photocatalytic and Electrocatalytic Processes. Energy Environ. Sci. 2013, 6, 3112-3135.

(2) Raciti, D.; Wang, C. Recent Advances in $\mathrm{CO}_{2}$ Reduction Electrocatalysis on Copper. ACS Energy Lett. 2018, 3, 1545-1556.

(3) Gattrell, M.; Gupta, N.; Co, A. A Review of the Aqueous Electrochemical Reduction of $\mathrm{CO}_{2}$ to Hydrocarbons at Copper. J. Electroanal. Chem. 2006, 594, 1-19.

(4) Kuhl, K. P.; Cave, E. R.; Abram, D. N.; Jaramillo, T. F. New Insights into the Electrochemical Reduction of Carbon Dioxide on Metallic Copper Surfaces. Energy Environ. Sci. 2012, 5, 7050-7059.

(5) Larrazábal, G. O.; Martín, A. J.; Krumeich, F.; Hauert, R.; PérezRamírez, J. Solvothermally-Prepared $\mathrm{Cu}_{2} \mathrm{O}$ Electrocatalysts for $\mathrm{CO}_{2}$ Reduction with Tunable Selectivity by the Introduction of p-Block Elements. ChemSusChem 2017, 10, 1255-1265.

(6) Martín, A. J.; Larrazábal, G. O.; Pérez-Ramírez, J. Towards Sustainable Fuels and Chemicals through the Electrochemical Reduction of $\mathrm{CO}_{2}$ : Lessons from Water Electrolysis. Green Chem. 2015, 17, 5114-5130.

(7) Choi, Y. W.; Mistry, H.; Roldan Cuenya, B. New Insights into Working Nanostructured Electrocatalysts through Operando Spectroscopy and Microscopy. Curr. Opin. Electrochem. 2017, 1, 95-103.

(8) Peterson, A. A.; Nørskov, J. K. Activity Descriptors for $\mathrm{CO}_{2}$ Electroreduction to Methane on Transition-Metal Catalysts. J. Phys. Chem. Lett. 2012, 3, 251-258.

(9) Hansen, H. A.; Varley, J. B.; Peterson, A. A.; Nørskov, J. K. Understanding Trends in the Electrocatalytic Activity of Metals and Enzymes for $\mathrm{CO}_{2}$ Reduction to CO. J. Phys. Chem. Lett. 2013, 4, 388-392.

(10) Peterson, A. A.; Abild-Pedersen, F.; Studt, F.; Rossmeisl, J.; Nørskov, J. K. How Copper Catalyzes the Electroreduction of Carbon Dioxide into Hydrocarbon Fuels. Energy Environ. Sci. 2010, 3, 13111315.

(11) Nie, X.; Esopi, M. R.; Janik, M. J.; Asthagiri, A. Selectivity of $\mathrm{CO}_{2}$ Reduction on Copper Electrodes: The Role of the Kinetics of Elementary Steps. Angew. Chem., Int. Ed. 2013, 52, 2459-2462.

(12) Nørskov, J. K.; Rossmeisl, J.; Logadottir, A.; Lindqvist, L.; Kitchin, J. R.; Bligaard, T.; Jónsson, H. Origin of the Overpotential for Oxygen Reduction at a Fuel-Cell Cathode. J. Phys. Chem. B 2004, 108, 17886-17892.

(13) Hussain, J.; Jónsson, H.; Skúlason, E. Faraday Efficiency and Mechanism of Electrochemical Surface Reactions: $\mathrm{CO}_{2}$ Reduction and $\mathrm{H}_{2}$ Formation on $\mathrm{Pt}(111)$. Faraday Discuss. 2016, 195, 619-636.

(14) Chan, K.; Nørskov, J. K. Electrochemical Barriers Made Simple. J. Phys. Chem. Lett. 2015, 6, 2663-2668.

(15) Xiao, H.; Cheng, T.; Goddard, W. A. Atomistic Mechanisms Underlying Selectivities in $\mathrm{C}_{1}$ and $\mathrm{C}_{2}$ Products from Electrochemical Reduction of $\mathrm{CO}$ on $\mathrm{Cu}(111)$. J. Am. Chem. Soc. 2017, 139, 130-136.

(16) Xiao, H.; Cheng, T.; Goddard, W. A.; Sundararaman, R. Mechanistic Explanation of the $\mathrm{pH}$ Dependence and Onset Potentials for Hydrocarbon Products from Electrochemical Reduction of $\mathrm{CO}$ on $\mathrm{Cu}(111)$. J. Am. Chem. Soc. 2016, 138, 483-486.

(17) Kortlever, R.; Shen, J.; Schouten, K. J. P.; Calle-Vallejo, F.; Koper, M. T. M. Catalysts and Reaction Pathways for the Electrochemical Reduction of Carbon Dioxide. J. Phys. Chem. Lett. 2015, 6, 4073-4082.
(18) Hori, Y.; Takahashi, R.; Yoshinami, Y.; Murata, A. Electrochemical Reduction of $\mathrm{CO}$ at a Copper Electrode. J. Phys. Chem. B 1997, 101, 7075-7081.

(19) Kas, R.; Kortlever, R.; Yılmaz, H.; Koper, M. T. M.; Mul, G. Manipulating the Hydrocarbon Selectivity of Copper Nanoparticles in $\mathrm{CO}_{2}$ Electroreduction by Process Conditions. ChemElectroChem 2015, 2, 354-358.

(20) Schouten, K. J. P.; Qin, Z.; Gallent, E. P.; Koper, M. T. M. Two Pathways for the Formation of Ethylene in CO Reduction on SingleCrystal Copper Electrodes. J. Am. Chem. Soc. 2012, 134, 9864-9867.

(21) Huang, J.; Hörmann, N.; Oveisi, E.; Loiudice, A.; De Gregorio, G. L. Potential-Induced Nanoclustering of Metallic Catalysts during Electrochemical $\mathrm{CO}_{2}$ Reduction. Nat. Commun. 2018, 9, 3117.

(22) Ren, D.; Fong, J.; Yeo, B. S. The Effects of Currents and Potentials on the Selectivities of Copper toward Carbon Dioxide Electroreduction. Nat. Commun. 2018, 9, 925.

(23) Hussain, J.; Jónsson, H.; Skúlason, E. Calculations of Product Selectivity in Electrochemical $\mathrm{CO}_{2}$ Reduction. ACS Catal. 2018, 8, 5240-5249.

(24) Li, C. W.; Kanan, M. W. $\mathrm{CO}_{2}$ Reduction at Low Overpotential on $\mathrm{Cu}$ Electrodes Resulting from the Reduction of Thick $\mathrm{Cu}_{2} \mathrm{O}$ Films. J. Am. Chem. Soc. 2012, 134, 7231-7234.

(25) Göttle, A. J.; Koper, M. T. M. Proton-Coupled Electron Transfer in the Electrocatalysis of $\mathrm{CO}_{2}$ Reduction: Prediction of Sequential vs. Concerted Pathways Using DFT. Chem. Sci. 2017, 8, $458-465$.

(26) Montoya, J. H.; Peterson, A. A.; Nørskov, J. K. Insights into C$\mathrm{C}$ Coupling in $\mathrm{CO}_{2}$ Electroreduction on Copper Electrodes. Chem CatChem 2013, 5, 737-742.

(27) Pegis, M. L.; Wise, C. F.; Koronkiewicz, B.; Mayer, J. M. Identifying and Breaking Scaling Relations in Molecular Catalysis of Electrochemical Reactions. J. Am. Chem. Soc. 2017, 139, 1100011003.

(28) Yoo, J. S.; Christensen, R.; Vegge, T.; Nørskov, J. K.; Studt, F. Theoretical Insight into the Trends That Guide the Electrochemical Reduction of Carbon Dioxide to Formic Acid. ChemSusChem 2016, 9, $358-363$.

(29) Huang, Y.; Deng, Y.; Handoko, A. D.; Goh, G. K. L.; Yeo, B. S. Rational Design of Sulfur-Doped Copper Catalysts for the Selective Electroreduction of Carbon Dioxide to Formate. ChemSusChem 2018, $11,320-326$.

(30) Shinagawa, T.; Larrazábal, G. O.; Martín, A. J.; Krumeich, F.; Pérez-Ramírez, J. Sulfur-Modified Copper Catalysts for the Electrochemical Reduction of Carbon Dioxide to Formate. ACS Catal. 2018, 8, 837-844.

(31) Eilert, A.; Cavalca, F.; Roberts, F. S.; Osterwalder, J.; Liu, C.; Favaro, M.; Crumlin, E. J.; Ogasawara, H.; Friebel, D.; Pettersson, L. G. M.; et al. Subsurface Oxygen in Oxide-Derived Copper Electrocatalysts for Carbon Dioxide Reduction. J. Phys. Chem. Lett. 2017, 8, 285-290.

(32) Mistry, H.; Varela, A. S.; Bonifacio, C. S.; Zegkinoglou, I.; Sinev, I.; Choi, Y. W.; Kisslinger, K.; Stach, E. A.; Yang, J. C.; Strasser, P.; et al. Highly Selective Plasma-Activated Copper Catalysts for Carbon Dioxide Reduction to Ethylene. Nat. Commun. 2016, 7, 12123.

(33) Lum, Y.; Ager, J. W. Stability of Residual Oxides in OxideDerived Copper Catalysts for Electrochemical $\mathrm{CO}_{2}$ Reduction Investigated with ${ }^{18} \mathrm{O}$ Labeling. Angew. Chem., Int. Ed. 2018, 57, $551-555$.

(34) Verdaguer-Casadevall, A.; Li, C. W.; Johansson, T. P.; Scott, S. B.; McKeown, J. T.; Kumar, M.; Stephens, I. E. L.; Kanan, M. W.; Chorkendorff, I. Probing the Active Surface Sites for CO Reduction on Oxide-Derived Copper Electrocatalysts. J. Am. Chem. Soc. 2015, 137, 9808-9811.

(35) The double layer capacitance values obtained by cyclic voltammetry after the $\mathrm{eCO}_{2} \mathrm{RR}$ testing (active surface areas) cannot account for the differences in catalytic performance.

(36) De Luna, P.; Quintero-Bermudez, R.; Dinh, C. T.; Ross, M. B.; Bushuyev, O. S.; Todorović, P.; Regier, T.; Kelley, S. O.; Yang, P.; 
Sargent, E. H. Catalyst Electro-Redeposition Controls Morphology and Oxidation State for Selective Carbon Dioxide Reduction. Nat. Catal. 2018, 1, 103-110.

(37) Xiao, H.; Goddard, W. A.; Cheng, T.; Liu, Y. Cu Metal Embedded in Oxidized Matrix Catalyst to Promote $\mathrm{CO}_{2}$ Activation and $\mathrm{CO}$ Dimerization for Electrochemical Reduction of $\mathrm{CO}_{2}$. Proc. Natl. Acad. Sci. U. S. A. 2017, 114, 6685-6688.

(38) Feng, X.; Jiang, K.; Fan, S.; Kanan, M. W. A Direct GrainBoundary-Activity Correlation for $\mathrm{CO}$ Electroreduction on $\mathrm{Cu}$ Nanoparticles. ACS Cent. Sci. 2016, 2, 169-174.

(39) The discrimination of chalcogenide phases $\left(\mathrm{CuX}\right.$ and/or $\mathrm{Cu}_{2} X$, $X=\mathrm{S}, \mathrm{Se}$ ) based on XPS is challenging due to the small difference in their binding energies acccording to the experimental determination, $0.2 \mathrm{eV}$; see ref 40 .

(40) The National Institute of Standards and Technology (NIST). X-ray Photoelectron Spectroscopy Database. DOI: 10.18434/ T4T88K.

(41) Cho, J. S.; Won, J. M.; Lee, J.-K.; Kang, Y. C. Design and Synthesis of Multiroom-Structured Metal Compounds-Carbon Hybrid Microspheres as Anode Materials for Rechargeable Batteries. Nano Energy 2016, 26, 466-478.

(42) Schreier, M.; Yoon, Y.; Jackson, M. N.; Surendranath, Y. Competition between $\mathrm{H}$ and $\mathrm{CO}$ for Active Sites Governs CopperMediated Electrosynthesis of Hydrocarbon Fuels. Angew. Chem., Int. Ed. 2018, 57, 10221-10225.

(43) Chernyshova, I. V.; Somasundaran, P.; Ponnurangam, S. On the Origin of the Elusive First Intermediate of $\mathrm{CO}_{2}$ Electroreduction. Proc. Natl. Acad. Sci. U. S. A. 2018, 115, E9261-E9270.

(44) Deng, Y.; Huang, Y.; Ren, D.; Handoko, A. D.; Seh, Z. W.; Hirunsit, P.; Yeo, B. S. On the Role of Sulfur for the Selective Electrochemical Reduction of $\mathrm{CO}_{2}$ to Formate on $\mathrm{CuS}_{\mathrm{x}}$ Catalysts. ACS Appl. Mater. Interfaces 2018, 10, 28572-28581.

(45) Taifan, W.; Boily, J. F.; Baltrusaitis, J. Surface Chemistry of Carbon Dioxide Revisited. Surf. Sci. Rep. 2016, 71, 595-671.

(46) Joo, J.; Uchida, T.; Cuesta, A.; Koper, M. T. M.; Osawa, M. Importance of Acid-Base Equilibrium in Electrocatalytic Oxidation of Formic Acid on Platinum. J. Am. Chem. Soc. 2013, 135, 9991-9994.

(47) Zeradjanin, A. R.; Grote, J. P.; Polymeros, G.; Mayrhofer, K. J. J. A Critical Review on Hydrogen Evolution Electrocatalysis: ReExploring the Volcano-Relationship. Electroanalysis 2016, 28, 22562269.

(48) Larrazábal, G. O.; Martín, A. J.; Pérez-Ramírez, J. Building Blocks for High Performance in Electrocatalytic $\mathrm{CO}_{2}$ Reduction: Materials, Optimization Strategies, and Device Engineering. J. Phys. Chem. Lett. 2017, 8, 3933-3944.

(49) Hori, Y.; Kikuchi, K.; Suzuki, S. Production of $\mathrm{CO}$ and $\mathrm{CH}_{4}$ in Electrochemical Reduction of $\mathrm{CO}_{2}$ at Metal Electrodes in Aqueous Hydrogencarbonate Solution. Chem. Lett. 1985, 14, 1695-1698.

(50) Phillips, K. R.; Katayama, Y.; Hwang, J.; Shao-Horn, Y. SulfideDerived Copper for Electrochemical Conversion of $\mathrm{CO}_{2}$ to Formic Acid. J. Phys. Chem. Lett. 2018, 9, 4407-4412.

(51) Roberts, F. S.; Kuhl, K. P.; Nilsson, A. Electroreduction of Carbon Monoxide over a Copper Nanocube Catalyst: Surface Structure and $\mathrm{pH}$ Dependence on Selectivity. ChemCatChem 2016, 8, 1119-1124.

(52) Varela, A. S.; Kroschel, M.; Reier, T.; Strasser, P. Controlling the Selectivity of $\mathrm{CO}_{2}$ Electroreduction on Copper: The Effect of the Electrolyte Concentration and the Importance of the Local $\mathrm{pH}$. Catal. Today 2016, 260, 8-13.

(53) To simulate a more negative potential on the surface, a spectator $\mathrm{K}$ atom was added to the surface to donate electronic density. This was largely transferred to the chalcogen atom.

(54) Torres, D.; López, N.; Illas, F.; Lambert, R. M. Low-Basicity Oxygen Atoms: A Key in the Search for Propylene Epoxidation Catalysts. Angew. Chem., Int. Ed. 2007, 46, 2055-2058.

(55) Álvarez-Moreno, M.; de Graaf, C.; López, N.; Maseras, F.; Poblet, J. M.; Bo, C. Managing the Computational Chemistry Big Data Problem: The ioChem-BDPlatform. J. Chem. Inf. Model. 2015, 55, 95-103. 